\title{
Effect of Sub Lethal Concentrations on Population Size of Termites Odontotermes Obesus (Rambur) and Coptotermes Heimi (Wasmann) Under Laboratory and Field Conditions
}

\author{
Khalid Zamir Rasib ${ }^{1}$, Ayesha Aihetasam ${ }^{1}$, Hina Ashraf ${ }^{1}$, Mohammad Afzal ${ }^{2}$ \\ ${ }^{1}$ Department of Zoology, University of the Punjab, Pakistan \\ ${ }^{1,2}$ Department of Biological Science, Forman Christian College University, Pakistan
}

Received: February 28, 2018; Published: March 12, 2018

*Corresponding author: Khalid Rasib, Department of Biological Science, Forman Christian College University, Lahore 54600, Pakistan, Tel: 0092423215559755; Email: khalidrasib786@gmail.com

\begin{abstract}
When termites Odontotermes obesus (Rambur) and Coptotermes heimi (Wasmann) were treated with toxicants using imidacloprid and fipronil at fixed sub lethal concentration of $0.3 \mathrm{ppm}$ and different group size $(10,25,50,100,125,150,200,250,300,350,400,450,500)$, then results revealed that greater the group size of the termite, a significantly $(\mathrm{P}<0.05)$ less mortality was observed. Such observation could be interpreted as resulting from a group effect or socially facilitated behavior. More generally, a group effect, or socially facilitated behavior, could be invoked: individuals may modulate their behavior in response to the presence of other group members through omnipresent signals or cues (by omnipresent signals, we mean signals that do not result from specific events in space or time).
\end{abstract}

Keywords: Coptotermes heimi; Group size; Odontotermes obesus, fipronil; imidacloprid; Sub Lethal; Concentration

\section{Introduction}

Termites are social insects of the order Isoptera now blattodea with about 3000 species Munthali [1]; Glaciela et al. [2], Tathiane in 281 genera Grohmann et al. [3], fifteen subfamilies and seven families Logan et al. [4], Pearce [5]. Termites are predominantly distributed in tropical environment, with the highest species richness in equatorial rainforest, and generally declining with increasing latitude Yanyong et al. [6]. Termites are dominant arthropod detritivores important in decomposition process. Their influence on decomposition processes at any site is likely to be governed to a large extent by the species composition and the local termite assemblage Jones and Eggleton [7]. Termite diversity, composition and their associated functions vary within and between ecosystems and these may shift under changing landuses Zeidler et al. [8]. Termites are often separated into two groups, "higher termites" and "lower termites". The group known as the "higher termites" (Termitidae), which makes up 75\% of all termite species, has only bacteria present in the gut. In the "lower termites" protozoan symbionts can be found in the gut in addition to bacteria Krishna [9]. These symbionts help with the digestion of cellulose.

The lower termites are generally more primitive, having simple galleries but not well formed nests (with the exception of a few Australian Coptotermes (Rhinotermitidae) which have mounds for nests). Some have colonies without true workers, and generally eat only wood. Unlike higher termites lower termites usually occur in more temperate latitudes. Higher termites (Termitidae) are much more diverse ecologically. While some still consume wood, others have evolved different diets of herbage, grass, dung, humus, fungus, lichens, or organic material in soil. The higher termites rely either on internal digestion with gut bacteria or external digestion in fungus combs Edwards and Mill [10]. The higher termites often build large nests or mounds, and are common in tropical areas, but are rare or absent in temperate climates. Odontotermes obesus (Rambur) is widely distributed in Pakistan, Bangladesh and India Akhtar et al. [11-13]. It is of great significance and feeds on wood, surface 
debris such as twigs, bark fragments, dry leaves and grasses. It is a common wood eater, damaging firewood, floor timber, wooden boxes, baskets and railway sleepers Akhtar [14].

In Pakistan this species has also been recorded to damage woodwork in buildings in various ecological areas. It attacks houses in villages more commonly than in urban areas Akhtar $[14,15]$. Termites become economically important pests when they started to destroy the wood and wooden products of human homes, building materials, forests, agriculture crops and other commercial products (Monica et al 2009). The major mound building termite species like Odontotermes obesus Rambur, 0. redemanni Wasmann, 0. wallonesis Wasmann, O. horni Wasmann, Heterotermes indicola Wasmann, Coptotermes kishori, C. heimi Wasmann, Microtermes obesi Holmgren, Trinervitermes biformis Wasmann and Microcerotermes beesoni Snyder attack the bark and heart wood of standing trees such as Butea monosperma (Lam.) Taub., Dipterocarpus indicus Bedd., Eucalyptus sp., Pterocarpus marsurpium Roxburgh, Santalum album L., Shorea robusta Roth., Terminalia bellirica (Gaertn.) Roxb. Swietenia macrophylla King., Dalbergia sissoo Roxb., Pinus wallichiana A. B. Jacks., Tectona grandis Linn.,Toona cilita M. Rome. Haldina cordifolia (Roxb.) Ridsdale etc. Rajagopal [16], Remadevi et al. [17,18] reported the possibility of CSI bait eliminating or suppressing the higher termite if the test colonies could pick up adequate lethal dose by installing more bait stations and prolonging the baiting period.

C. heimi has large population size, a subterranean termite colony can cause more structural damage in a shorter time. Wood products that are infested by subterranean termite may be recognized by tapping the wood with a hard object. In severe infestations, subterranean termite hollows out woods leaving a paper-thin surface. Because of its population size and foraging range, the presence of subterranean termite colonies poses serious threats to nearby structures. Once established, subterranean termite has never been eradicated from an area. Another characteristic of subterranean termite is carton nest material that is made of termite excrements, chewed wood, and soil. Grace et al. [19]. In fact, social interactions are so effective in minimizing deleterious actions of strong stresses such as starvation and disease, one could hypothesize that they would also impact survivorship of termites imposed to insecticides [20]. This work tests such a hypothesis, comparing the survivorship of poisoned and non-poisoned termites which have been confined in groups of different sizes Miramontes and De Souza [21]. Therefore, current research focusing on the effect of sub lethal concentrations on population size of termites Odontotermes obesus (Rambur) and Coptotermes heimi (Wasmann) under laboratory and field conditions.

\section{Materials and Methods}

\section{Experimental Organism}

A) Collection of Odontotermes obesus and Coptotermes heimi

O.obesus and C. heimi were collected from different areas of district Lahore including visits to Changa Manga forest, Jallo Park,
Wagha border, Ravi siphon, Jinnah garden, agricultural crops and fallen wooden logs infested under natural conditions. They were also collected through the baiting of different woods as stakes with appropriate dimensions and supplemented by sugarcane stalk to aggregate maximum termites. Collection were made also feasible by using artificial baiting methods like bucket traps / wetted toilet rolls/ card boards consisting of plastic bottles with small holes at the base as well as on lateral sides to permit the entry of termites into the bait. The baits were buried into the soil to their quarter length followed by regular inspection twice a month. This will be helpful to collect termites as and when they are visiting to the bait feeding stations.

\section{Augmentation}

Colonies of 0 . obesus and C. heimi were established in a transparent test apparatus made up of acrylic sheet with specific dimensions (Length $\times$ height $\times$ width: $30 \times 35 \times 30 \mathrm{~cm}$ ) under laboratory conditions. Wood blocks (length $\times$ Width $\times$ thickness: $30 \times 4 \times 2 \mathrm{~cm}$ ) of Populus euramericana, which is one of the most susceptible wood were cleaned, and kept in a dry place before their use for one week. $2000 \mathrm{~g}$ of sterile soil/sand was added along with 300 termite workers, 50 soldiers and 100 alate pairs in each transparent cage containing four tiers of Populus euramericana blocks. The termites were handled with a moist paint brush. Workers of a uniform stage were used, their morphology. Buchli and their stomach contents were used to judge whether or not they were functional workers. All the cages were then covered with black polythene/cloth to minimize the effects of light and placed in the controlled room at $26^{\circ} \mathrm{C}$, RH $75 \%$. Moisture in the containers was kept judiciously and checked twice a month.

\section{Insecticides/ Toxicants}

Commercial formulation of two insecticides used for the bioassays were, Fipronil (Fiprostar® 25 EC Starlet International) and Imidacloprid (Mirage ${ }^{\circ}$ 5\% SC Ali Akbar Enterprises, Pakistan) at lower concentration of $0.3 \mathrm{ppm}$. The base line concentration $0.3 p p m$ for both toxicants was selected separately by diluting the termiticides formulation (based on the solubility) in solvents (acetone or distilled water) to obtain desired concentrations.

\section{Laboratory Bioassay}

Population size of two different termites i.e. Odontotermes obesus and Coptotermes heimi was checked under laboratory conditions. Selected size ranges were 10, 25, 50, 100, 125, 150, 200, $250,300,350,400,450$ and 500 respectively. Only healthy workers of two species were used and acclimatized to laboratory conditions at $26+1^{\circ} \mathrm{C}$ and $75 \% \mathrm{RH}$ for two days prior to bioassay. The filter paper was treated with $0.3 \mathrm{ppm}$ of fipronil and imidacloprid and allowed to dry for three hours while water was used as control treatment. After drying, they were placed in Petri dishes $(70 \mathrm{~mm}$ diameter, $20 \mathrm{~mm}$ height), and left in an incubator at $25 \pm 2{ }^{\circ} \mathrm{C}$ in the dark conditions to assess the impact of concentration on group survival and consumption. The bioassay lasted two weeks. The experiments were carried out in triplicate using different size ranges. Mortality data were submitted to probit analyses. The 
corrected mortality was estimated by the difference between total death in the treatment and the control.

\section{Field No Choice bioassay}

The wood Populus euramericana was treated with sublethal concentration of $0.3 \mathrm{ppm}$ of fipronil and imidacloprid and a separate control without treattment was placed separately for both termite Odontontermes obesus and Coptotermes heimi species. All woods were placed in their nests separately at Wagha border $30 \mathrm{~km}$ away from Pakistan in an undisturbed area. Three replicates $(n=3)$ for each concentration were used for each species. The test lasted for 2 weeks under field conditions and after that Average wood consumption was recorded in each case after removal of all debris and reincubated at $60 \mathrm{C} 0$ for one day and then post weight recorded. The wood consumption was taken as a measure of termite density and feeding activity in each case.

\section{Data Analysis}

Mean percentage survival of Odontotermes obesus and Coptotermes heimi at different population sizes at $0.3 \mathrm{ppm}$ concentration of fipronil and Imidacloprid. Statistically results were at $\mathrm{P}=0.05$ (Tukey's test).

\section{Results}

\section{Effect of Sub Lethal Concentration on Population Size of Termites Under Laboratory Condition}

When different population sizes i.e. $10,25,50,100,125,150$, $200,250,300,350,400,450$ and 500 of Odontotermes obesus and

Table 1: Mean survival ( \pm S.D) of Odontotermes obesus at different population sizes at $0.3 \mathrm{ppm}$ concentration of imidacloprid and fipronil under lab condition.

\begin{tabular}{|c|c|c|c|c|}
\hline \multirow{2}{*}{$\begin{array}{c}\text { Population } \\
\text { Siz } \\
\end{array}$} & \multirow{2}{*}{$\begin{array}{c}\text { Odontotermes obesus } \% \\
\text { Imidacloprid }\end{array}$} & \multicolumn{3}{|c|}{ Mean survival ( \pm S.D) of Odontotermes obesus } \\
\hline & & Fipronil & Imidacloprid & Fipronil \\
\hline 10 & 20 & 10 & $2 \pm 0.2^{\mathrm{a}}$ & $1 \pm 0.26^{\mathrm{a}}$ \\
\hline 25 & 72 & 64 & $18 \pm 0.40^{b}$ & $16 \pm 0.46^{b}$ \\
\hline 50 & 76 & 66 & $38 \pm 0.15^{c}$ & $33 \pm 0.53^{c}$ \\
\hline 100 & 79 & 70 & $79 \pm 0.62^{d}$ & $70 \pm 0.3^{d}$ \\
\hline 125 & 80 & 68 & $99 \pm 0.44^{\text {e }}$ & $85 \pm 0.26^{\mathrm{e}}$ \\
\hline 150 & 79 & 65.3 & $118 \pm 0.61^{\mathrm{f}}$ & $98 \pm 0.46^{f}$ \\
\hline 200 & 77 & 69 & $154 \pm 0.75^{g}$ & $137 \pm 0.26^{\mathrm{g}}$ \\
\hline 250 & 78 & 74 & $194 \pm 0.76^{\mathrm{h}}$ & $185 \pm 0.36^{\mathrm{h}}$ \\
\hline 300 & 78 & 65 & $234 \pm 0.21^{\mathrm{i}}$ & $195 \pm 0.26^{\mathrm{i}}$ \\
\hline 350 & 78 & 57 & $272 \pm 0.45^{j}$ & $200 \pm 0.26^{j}$ \\
\hline 400 & 77 & 72 & $308 \pm 0.56^{\mathrm{k}}$ & $288 \pm 0.26^{\mathrm{k}}$ \\
\hline 450 & 78 & 69 & $348 \pm 0.61^{1}$ & $301 \pm 0.53^{1}$ \\
\hline 500 & 80 & 68 & $396 \pm 0.51^{\mathrm{m}}$ & $340 \pm 0.36^{\mathrm{m}}$ \\
\hline
\end{tabular}

\section{Effect of Toxicants on the Population Size of Termites under Field Conditions}

When $0.3 p p m$ of imidacloprid and fipronil were tested against Odontotermes obesus and Coptotermes heimi under field conditions after two weeks, maximum consumption on wood blocks of Populus euramericana were observed. These observations indicate that
Coptotermes heimi were tested under laboratory conditions against $0.3 \mathrm{ppm}$ of imidacloprid and fipronil it was observed that with the increase in size the rate of survival increases in both termites. In case of 0 . obesus, when imidacloprid is employed the highest survival rate was observed at 500 population size with $396 \pm 0.51$ survival rate while lowest survival was noted at 10 with $2 \pm 0.2 \%$. However, at other sizes the mean survival was as follow: $18 \pm 0.40$, $38 \pm 0.15,79 \pm 0.62,98 \pm 0.44,118 \pm 0.61,154 \pm 0.75,194 \pm 0.76$, $234 \pm 0.21,272 \pm 0.45,308 \pm 0.56$ and $348 \pm 0.61$ respectively. On other hand, when fipronil was used against 0 . obesus similar results were observed the maximum survival $340 \pm 0.36 \%$ was at 500 while minimum survival was $1 \pm 0.26 \%$ at 10 .

Whereas, the average rate of survival on others was as follow: $16 \pm 0.46,33 \pm 0.53,70 \pm 0.3,85 \pm 0.26,98 \pm 0.46,137 \pm 0.26,185 \pm 0.36$, $195 \pm 0.26,200 \pm 0.26,288 \pm 0.26$ and $301 \pm 0.53 \%$ respectively (Table 1). When C. heimi was treated with imidacloprid it was observed that at size of 500 maximum survival was achieved with $410 \pm 0.46$ and at size of 10 minimum termites were survived which was $3 \pm 0.2$. While in rest of sizes the rate of survival was $20 \pm 0.44,40 \pm 0.36$, $85 \pm 0.1, \quad 101 \pm 0.26, \quad 125 \pm 0.36, \quad 159 \pm 0.36, \quad 199 \pm 0.36, \quad 240 \pm 0.2$, $278 \pm 0.56,318 \pm 0.3$ and $355 \pm 0.1$ respectively. Similar results were analyzed when fipronil is used against various sizes of $C$. heimi. At highest and lowest sizes the rate of survival was $352 \pm 0.3$ and $4 \pm 0.44$ respectively. Whereas in rest of other sizes the rate of survival is depicted as: $16 \pm 0.46,33 \pm 0.53,70 \pm 0.3,85 \pm 0.26,98 \pm 0.46$, $137 \pm 0.26,185 \pm 0.36,195 \pm 0.26,200 \pm 0.26,288 \pm 0.26,301 \pm 0.53$ and $340 \pm 0.36$ respectively (Table 2 ). Statistically results were sinificant at $(\mathrm{P}<0.05)$ usung Tukey,s Test.

as a result of treatment using respective chemicals have shown simply repellency. Imidacloprid is a neonicotinoid insecticide in the chloronicotinyl nitroguanidine chemical family. Imidacloprid acts on several types of post-synaptic nicotinic acetylcholine receptors in the nervous system. In insects, these receptors are located only within the central nervous system. Following binding to the 
nicotinic receptor, nerve impulses are spontaneously discharged at first, followed by failure of the neuron to propagate any signal. Sustained activation of the receptor results from the inability of acetylcholinesterases to break down the pesticide. This binding process is irreversible.

Table 2: Mean survival ( \pm S.D) of Coptotermes heimi at different population sizes at 0.3ppm concentration of imidacloprid and fipronil under lab condition.

\begin{tabular}{|c|c|c|c|c|}
\hline Population & \multicolumn{2}{|c|}{ Coptotermes heimi \% } & \multicolumn{2}{c|}{ Mean survival ( \pm S.D) of Coptotermes heimi } \\
\hline Size & imi & fipronil & imidacloprid & fipronil \\
\hline 10 & 30 & 40 & $3 \pm 0.2 \mathrm{a}$ & $4 \pm 0.44 \mathrm{a}$ \\
\hline 25 & 80 & 48 & $20 \pm 0.44 \mathrm{~b}$ & $12 \pm 0.36 \mathrm{~b}$ \\
\hline 50 & 80 & 66 & $40 \pm 0.36 \mathrm{c}$ & $33 \pm 0.26 \mathrm{c}$ \\
\hline 100 & 85 & 69 & $101 \pm 0.26 \mathrm{e}$ & $85 \pm 0.31 \mathrm{~d}$ \\
\hline 125 & 81 & 68 & $125 \pm 0.36 \mathrm{f}$ & $105 \pm 0.34 \mathrm{f}$ \\
\hline 150 & 84 & 70 & $159 \pm 0.36 \mathrm{~g}$ & $145 \pm 0.32 \mathrm{~g}$ \\
\hline 200 & 80 & 73 & $240 \pm 0.2 \mathrm{i}$ & $182 \pm 0.2 \mathrm{i}$ \\
\hline 250 & 80 & 73 & $278 \pm 0.56 \mathrm{j}$ & $210 \pm 0.26 \mathrm{j}$ \\
\hline 300 & 80 & 70 & $318 \pm 0.3 \mathrm{k}$ & $230 \pm 0.36 \mathrm{k}$ \\
\hline 400 & 80 & 66 & $355 \pm 0.1 \mathrm{l}$ & $300 \pm 0.42 \mathrm{l}$ \\
\hline 450 & 80 & 75 & $410 \pm 0.46 \mathrm{~m}$ & $324 \pm 0.47 \mathrm{~m}$ \\
\hline 500 & 79 & 72 & 71 & $352 \pm 0.3 \mathrm{n}$ \\
\hline
\end{tabular}

Note: Different letters indicated above vertically against each chemical indicated a significant differences when applied to anova 1 way analysis at $5 \%(\mathrm{P}<0.05)$ (Tukey's Test).

Since imidacloprid is slow acting toxicant and therefore termite consumed more of the wood as compared to control. Imidacloprid is a systemic insecticide, which means that plants take it up from the soil or through the leaves and it spreads throughout the plant's stems, leaves, fruit, and flowers. Insects that chew or suck on the treated plants end up eating the imidacloprid as well. Once the insects eat the imidacloprid, it damages their nervous system and they eventually die. Imidacloprid disrupts the nerve's ability to send a normal signal, and the nervous system stops working the way it should. Imidacloprid is much more toxic to insects and other invertebrates than it is to mammals and birds because it binds better to the receptors of insect nerve cells. This is similar in the case of field studies. In case of O.obesus, highest consumption was observed in blocks treated with imidacloprid i.e.: $82.5 \pm 0.53 \mathrm{mg}$

Table 3: Average wood consumption $( \pm$ S.D) by Odontotermes obesus treated at $0.3 p p m$ concentration of imidacloprid and fipronil under field conditions after two weeks under no choice bioassay.

\begin{tabular}{|c|c|c|}
\hline \multirow{2}{*}{ Wood Used } & \multicolumn{2}{|c|}{ Average wood consumption(mg) after 2 week } \\
\cline { 2 - 3 } & \multicolumn{2}{|c|}{ Odontotermes obesus } \\
\cline { 2 - 3 } & imidacloprid & $70.5 \pm 0.63$ \\
\hline Populus euramericana & $82.5 \pm 0.53$ & $78.4 \pm 0.54$ \\
\hline Control & $86.5 \pm 0.45$ & Fipronil \\
\hline
\end{tabular}

\section{Discussion}

\section{Effect of Sub Lethal Concentration on the Population Size of Termites}

Termites' control was based purely in recent past on chemicals especially synthetic insecticides. The satisfactory control of whereas it was $70.5 \pm 0.6 \mathrm{mg}$ in fipronil as compared control where maximum activity was recorded (Table 3 ).

This might be the difference in chemicals used with variable repellecy against termites. Although fast acting fipronil vs. slow acting imdacloprid might be the reason. However, similar results were observed with C.heimi where maximum consumption on wood blocks were recorded in imidacloprid, $65.5 \pm 0.55 \mathrm{mg}$ and minimum in case of fipronil i.e. $60.4 \pm 0.53 \mathrm{mg}$ respectively as compares to control, where maximum wood consumption was recorded. This wood consumption treated with insecticide is apparently low in case of fipronil than imidacloprid, suggesting high toxicity of fipronil under field conditions than imidacloprid (Tables 3 \& 4). termites in agro-ecosystem was mainly dependent upon persistent organochlorine (OC) insecticides. The restriction on cyclodiene (=OC) insecticides closed a chapter from history of termites control and underscored dire need for alternative insecticides, which would have economic viability, environmental acceptability, abundant availability, consumer safety and termiticidal efficacy 
Khan and Singh [22], Anonymous [23]. Today many safe and simple practices of termites' management including cultural and biological control, queen removal, plant resistance, natural products, physical barriers and baiting systems have been proposed but insecticides are still playing a key role for the termites' control. Chemicals like chlorpyrifos, thiodan, cypermethrin, imidacloprid, fipronil, carbosulfan and triazophos are being recommended Kumawat [24] Rana et al. [25].

Table 4: Average wood consumption ( \pm S.D) by Coptotermes heimi treated at $0.3 p p m$ concentration of imidacloprid and fipronil under field conditions after two weeks under no choice bioassay.

\begin{tabular}{|c|c|c|}
\hline \multirow{2}{*}{ Wood Used } & \multicolumn{2}{|c|}{ Average wood consumption(mg) after 2 week } \\
\cline { 2 - 3 } & \multicolumn{2}{|c|}{ Coptotermes heimi } \\
\cline { 2 - 3 } & Imidacloprid & $60.4 \pm 0.53$ \\
\hline Populus euramericana & $65.5 \pm 0.55$ & $68.4 \pm 0.41$ \\
\hline Control & $80.4 \pm 0.43$ & \\
\hline
\end{tabular}

The control of subterranean termites through the use of conventional and highly persistent insecticides caused severe public health and environmental concerns Pearce [5]. In the present study we evaluated the toxicities of two insecticides having novel modes of action against Odontotermes obesus and Coptotermes heimi collected from the different localities of Lahore, Pakistan. For effective and fast control of termite population synthetic pesticides are used, which show very high lethality in different termite species. In the present study fipronil and imidacloprid are used to control termites i.e. Odontotermes obesus and Coptotermes heimi. The result indicates that with higher population size the survival rate of termite's increases as in case of o. obesus when imidacloprid is employed at 500 population size survival rate was $396 \pm 0.51 \%$ however in case of ten termites survival was $2 \pm 0.2 \%$ only. Whereas, regarding fipronil survival at 500 was $340 \pm 0.36$ and at $10,1 \pm 0.26$ $\%$ was recorded. Same results were calibrated for C.heimi where in case of imidacloprid at greater and smaller size $410 \pm 0.46 \%$ and $3 \pm 0.2 \%$ survival was observed however $352 \pm 0.3$ and $4 \pm 0.44 \%$ was showed by fipronil. The reason is the trophallaxis and grooming. However fipronil is comparatively faster than imidacloprid.

Saran and Rust [26] found that Reticulitermes flavipes tunneled through untreated sand and stopped near the interface of fipronil treated sand. There was little tunneling in the treated sand, but termites tunneled close enough to obtain a lethal dose of fipronil. To some extent $C$. formosanus and Reticulitermes flavipes penetrated sand treated with 0-64 ppm fipronil, indicating non-repellency, but complete penetration of the treated sand was prevented by high mortality ( $\geq 88 \%$ for $C$. formosanus and $\geq 89 \%$ for R. flavipes after 7days) Remmen and Su [27]. While several studies conducted in small laboratory arenas have found high mortality in fipronil treatments, extended foraging arena assays demonstrated that fipronil barriers can split termite populations, with high mortality occurring close to the treatment site, but little mortality at distances $>5 \mathrm{~m} \mathrm{Su}$ [27]. Although imidacloprid is slow to induce mortality, mobility impairment occurs within hours of exposure Thorne and Breisch [28]. Imidacloprid is non-repellent Remmen and Su [27], but this combination of delayed mortality and rapid mobility impairment results in limited movement of termites into treated barriers and limited mortality after 7 days in close proximity to imidacloprid-treated sand.
Horwood [29] found that after 15 months, chlorpyrifos and fipronil concentrations at lower depths were little changed from the time of treatment, but there was a major reduction in imidacloprid concentration at all depths. Cai and Henderson [30] their results show that the presence of $C$. formosanus can suppress the growth of Bti and Btt and the suppression effect enhanced with increased of group size. Fipronil is a broad-spectrum phenylpyrazole insecticide. Fipronil is used to control ants, beetles, cockroaches, fleas, ticks, termites, mole crickets, thrips, rootworms, weevils, and other insects. Fipronil kills insects when they eat it or come in contact with it. Fipronil works by disrupting the normal function of the central nervous system in insects. Fipronil belongs to the phenylpyrazole class of insecticide (IRAC 2008). It is known to inhibit the neurotransmitter $\gamma$-aminobutyric acid (GABA) in both insects and vertebrates Hosie et al. [31,32] Tingle et al. [33]. Fipronil and imidacloprid, as non-repellent insecticides, have attracted more interest than traditional repellent insecticides Kard et al. [34-37].

Non-repellent insecticides often maintain the property of nonrepellency even at high concentrations (up to 500 part per million in Reticulitermes flavipes Saran and Rust [26]. Fipronil is more toxic to insects than people and pets because it is more likely to bind to insect nerve endings through contact toxicity. It's possible that inter colony differences in to trophallaxis or grooming may exist. With fipronil and imidacloprid comparison, of mortality to control did not indicate that termite exposed to $0.3 \mathrm{ppm}$ of either insecticide were consistently successful in transferring a lethal concentration to termites. This also suggesting that even longer exposure to low insecticide concentrations might lead to greater incidence of lethal transfer, so long as sufficient no of termites remained alive for better transfer of lethality. Osbrink et al. [38] did not find significant differences in LT50 values among workers from different colonies exposed to fipronil.The transfer of fipronil among termites can be caused by body contract, mutual grooming and trophallaxis Song and Hu [39], Saran and Rust [26].

It could be argued that the larger the groups, the more are the tasks such as allogrooming and trophallaxis shared, decreasing each individuals work (stress) load, hence giving it a greater chance to cope with the insecticide effects. Jones [7], studying termite 
tunnelling through treated soil, proposed a similar mechanism to explain why larger groups of termites could tunnel deeper than smaller ones, with relative mortality being lower in larger groups. It was claimed that the larger the group, the more could tasks be shared, giving more individuals at any time the chance to loaf, rather than having to be involved in tunneling and maintenance tasks most of the time, as in small groups [40-44]. Our results have important practical implications, too. Laboratory experiments with termites/ insecticides, for instance, may be severely affected by the group size being tested, providing that social facilitation has a significant impact on the outcome of the termite response to poisoning [4546]. Tests performed on groups above/below optimal density may overestimate the effect of the insecticide, restricting the relevance of such studies to the field. Further studies are needed in order tofully understand all the mechanisms involved.

\section{Conclusion}

Current study indicates that greater the size of population, greater the survival recorded in both of the species. Such observation could be interpreted as resulting from a group effect or socially facilitated behavior. More generally, a group effect, or socially facilitated behavior, could be invoked: individuals may modulate their behavior in response to the presence of other group members through omnipresent signals or cues (by omnipresent signals, we mean signals that do not result from specific events in space or time).The study has not only enabled an in-depth study of the cryptic behavior of termites, but also facilitated experiments on the enumeration of termite populations. The effect of imidacloprid seems more slow than firpronil being a fast acting toxicant. At present internationally more slow acting toxicants are used with their variable toxicity and repellency for more effective termite control. The results indicate that the efficacy of fipronil may be affected by the presence of imidacloprid in the field. Question that remain to be investigated include the mechanism of transfer (grooming, trophallaxis or both), influence of caste (e.g soldiers) ans caste proportion on transfer and basis of differences in termite susceptibility and variability.

\section{Acknowledgment}

This work is supported by Pakistan science Foundation Islamabad and Funds received are greatly acknowledge and appreciated. We gratefully acknowledge anonymous referees for their critical reading that helped improve the manuscript.

\section{References}

1. Munthali DC, Logan JWM, Wood TG, Nyirenda GKC (1999) Termite distribution and damage to crops on small holder farms in southern Malawi. International Journal of Tropical Insect Science 19(1): 43-49.

2. Glaciela K, Julio CP, Jaime AA, Deise CS (2006) Termite Activity in Relation to Natural Grassland Soil Attributes. Scientia Agricola 63(6): 583-588.

3. Grohmann C, Oldeland J, J Stoyan D, Linsenmair KE (2010) Multi-scale pattern analysis of a mound-building termite species. Insect Sociaux 57(4): 477-486.

4. Logan JW, Cowie RH, Wood TG (1990) Termite (Isoptera) control in agriculture and forestry by non-chemical methods: a review. Bulletin of entomological research 80(3): 309-330.
5. Pearce MJ (1997) Termites: Biology and Pest Management. CAB International, New York, USA, pp. 172.

6. Yanyong C Ouab S, Nit K (2003) Belt-Transect: A sampling Device for Termite Communities Study. Kasetsart J 37: 150-156.

7. Jones SC (1990) Effects of population-density on tunnelling by Formosan subterranean termite (Isoptera, Rhinotermitidae) through treated soil. Journal of Economic Entomology 83(3): 875-878.

8. Zeidler J Hanrahan S, Scholes M (2002) Termite species richness, composition and diversity on five farms in southern Kunene region, Namibia. African Zoology 37(1): 7-11.

9. Krishna K (1969) In Krishna K, Weesner FM (Eds.) Biology of termites, I Academic Press, London and New York, USA, pp. 598.

10. Edwards R, Mill AE (1986) Termites in Buildings. Their biology and control. The Rentokil Library, Rentokil Ltd, East Grinstead, UK pp. 261.

11. Akhtar MS (1972) Studies on the Taxonomy and zoogeography of the termites of Pakistan. Thesis, University of the Punjab, Lahore, Pakistan.

12. Akhtar MS (1975) Taxonomy and zoogeography of the termites (Isoptera) of Bangladesh. Bull Dept Zool University Punjab (NS): 1-199.

13. Chhotani OB, Das BC (1979) Variability and morphometric analysis of the soldier caste in Heterotermes indicola (Wasmann). Proc Symp Zool Surv India 1: 47-52.

14. Akhtar MS (1981) Some observations on swarming and development of incipient colonies of termites of Pakistan. Pakistan J Zool 10: 283-290.

15. Akhtar MS (1991) Feeding responses to wood and wood extracts by Bifiditermes beesoni (Gardner) (Isoptera: Kalotermitidae) Int Biodet Bull 17: 21-25.

16. Rajagopal D (2002) Economically important termite species in India. Sociobiology 41: 33-46.

17. Remadevi OK, Nagaveni HC, Muthukrishnan R, Vijayalakshmi G (2005) Natural resistance of wood of Cleistanthus collinus (Roxb.) Benth and Hook against wood decay fungi and termites. Journal of the Indian Academy of Wood Science 2: 45-50.

18. Lee CC, Neoh KB, Lee CY (2014) Colony Size Affects the Efficacy of Bait Containing Chlorfluazuron Against the Fungus-Growing Termite Macrotermes gilvus (Blattodea: Termitidae). Journal of economic entomology 107(6): 2154-2162.

19. Grace JK, Tome CHM, Shelton TG, Oshiro RJ, Yates JR (1996) Baiting studies and considerations with Coptotermes formosanus (Isoptera: Rhinotermitidae) control in Hawaii. Sociobiology 28(3): 511-520.

20. Grace JK, Tome CHM, Shelton TG, Oshiro RJ, Yates III JR (1996) Baiting studies and considerations with Coptotermes formosanus (Isoptera: Rhinotermitidae) control in Hawaii. Sociobiology 28(3): 511-520.

21. De Souza 0, Miramontes O, Santos CA, Bernardo DL (2000) Social facilitation affecting tolerance to poisoning in termites (Insecta, Isoptera). Insectes soc 48(1): 21-24.

22. Khan RM, Singh AP (1985) Control of termites in wheat crop with insecticides applied through irrigation. Entomon 10: 197-201.

23. Anonymous (2000) Finding Alternatives to Persistent Organic Pollutants (PoPs) for Termite Management. Global IPM Facility Expert Group on Termite Biology and Management. Stockholm Convention. Food and Agriculture Organization, Rome 118-168.

24. Kumawat KC (2001) Evaluation of some insecticides against field termites Odontotermes obesus and Microtermes obesi in wheat, Triticum aestivum. Pakistan Journal of Entomology 9: 51-53.

25. Rana J Ombir S, Dahiya KK (2001) Management of termite, Microtermes obesi (Holmgren) in wheat, Triticulum aestivum through seed treatment. Annales de biologie Clinique 17: 207-209. 
26. Saran RK, Rust MK (2007) The toxicity, uptake, and transfer efficiency of fipronil in western subterranean termites (Isoptera: Rhinotermitidae). Journal of economic entomology 100(2): 495-508.

27. Remmen LN, Su NY (2005) Tunneling and mortality of eastern and Formosan subterranean termites (Isoptera: Rhinotermitidae) in sand treated with thiamethoxam or fipronil. Journal of economic entomology 98(3): 906-910.

28. Thorne BL, Breisch NL (2001) Effects of sublethal exposure to imidacloprid on subsequent behavior of subterranean termite Reticulitermes virginicus (Isoptera: Rhinotermitidae). Journal of economic entomology 94(2): 492-498.

29. Horwood MA (2007) Rapid degradation of termiticides under field conditions. Australian journal of Entomology 46(1): 75-78.

30. Cai W, Henderson G (2013) Evidence of Formosan Subterranean Termite Group Size and Associated Bacteria in the Suppression of Entomopathogenic Bacteria, Bacillus thuringiensis subspecies israelensis and thuringiensis. Annals of the Entomological Society of America 106(4): 454-462.

31. (2008) IRAC, IRAC mode of action classification.

32. Hosie AM, Baylis HA, Buckingham SD, Sattelle DB (1995) Actions of the insecticide fipronil on dieldrin-sensitive and -resistant GABA receptors of Drosophila melanogaster. British Journal of Pharmacology 116: 909 912.

33. Tingle CC, Rother JA, Dewhurst CF, Lauer S, King WJ (2003) Fipronil: environmental fate, ecotoxicology, and human health concerns. Reviews of Environmental Contamination and Toxicology 176: 1-66.

34. Kard B (2001) Gulfport studies stay the course. Pest Control 69: 30-33.

35. Henderson G (2003) Liquid learning. Pest Control 31: 48-50.

36. Ibrahim SA, Henderson G, Fei H (2003) Toxicity, repellency, and horizontal transmission of fipronil in the Formosan subterranean termite (Isoptera: Rhinotermitidae). Journal of Economic Entomology 96(2): 461-467.

37. Shelton TG, Grace JK (2003) Effects of exposure duration on transfer of nonrepellent termiticides among workers of Coptotermes formosanus
Shiraki (Isoptera: Rhinotermitidae). Journal of Economic Entomology 96(2): 456-460.

38. Osbrink WLA, Lax AR, Brenner RJ (2001) Insectide suceptibility in Coptotermes formosanus and Reticulitermes virginicus(Isoptera: Rhinotermitidae). Journal of economic entomology 94(5): 1217-1228.

39. Song D, Hu XP (2006) Effects of dose, donor-recipient interaction time and ratio on fipronil transmission among the Formosan subterranean termite nestmates (Isoptera: Rhinotermitidae). Sociobiology 48(2): 237-246.

40. Ching Chen Lee, Kok Boon Neoh, Chow Yang Lee (2014) Colony Size Affects the Efficacy of Bait Containing Chlorfluazuron Against the Fungus-Growing Termite Macrotermes gilvus (Blattodea: Termitidae). Journal of economic entomology 107(6): 2154-2162.

41. Kaschuk G, Santos JCP, Almeida JA, Sinhorati DC, Berton Junior JF (2006) Termite activity in relation to natural grassland soil attributes. Scientia Agricola 63(6): 583-588.

42. Verma M, Sharma S, Prasad R (2009) Biological alternatives for termite control: a review. International Biodeterioration and Biodegradation 63(8): 959-972.

43. Richard JF, Baddi GA, Costa C, Guiresse M, Kaemmerer M, et al. (2006) Comparative study on humic acids of the mound of a wood-feeding termite and of the litter directly below in the Amazon river delta. Journal of Chemistry Ecological 22: 201-209.

44. Su NY (2005) Response of the Formosan subterranean termites (Isoptera: Rhinotermitidae) to baits or non repellent termiticides in extended foraging arenas. Journal of economic entomology 98(6): 21432152.

45. Sarcinelli TS, Schaefer CEG, de Souza Lynch L, Arato HD, Viana JHM, et al. (2009) Chemical, physical and micromorphological properties of termite mounds and adjacent soils along a toposequence in Zona da Mata, Minas Gerais State, Brazil. Catena 76(2): 107-113.

46. Thorne BL, Russek Cohen E, Forschler BT, Breisch NL, Traniello JF (1996) Evaluation of mark-release-recapture methods for estimating forager population size of subterranean termite (Isoptera: Rhinotermitidae) colonies. Environmental Entomology 25(5): 938-951.
(C) This work is licensed under Creative

Submission Link: https://biomedres.us/submit-manuscript.php

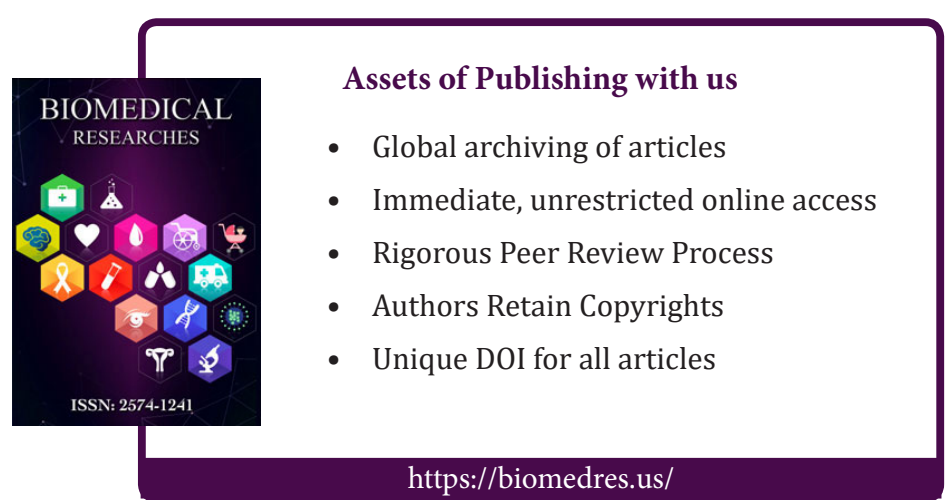

